\title{
3-D Structural Changes in Subchondral Bone and the Effect of Bisphosphonate Intervention in Early Osteoarthritis
}

\author{
Cambios Estructurales Tridimensionales del Hueso Subcondral y el Efecto \\ de la Intevención con Bisfosfonato en la Osteoartritis Temprana
}

Hainan Chen*; Qirong Dong* \& Wei Jiang**

CHEN, H.; DONG, Q. \& JIANG, W. 3-D Structural changes in subchondral bone and the effect of bisphosphonate intervention in early osteoarthritis. Int. J. Morphol., 34(1):291-297, 2016.

SUMMARY: This study aims to observe the 3-D structural changes in subchondral bone and the effects of bisphosphonate intervention in the early unsteady stage of the knee joint. Sixty healthy male New Zealand white rabbits were divided into the model group $(n=24)$, the bisphosphonate (Bis) group $(n=24)$, and the control group $(n=12)$. The rabbits' right knees were used to evaluate the structural changes. The Bis group received subcutaneous injections of bisphosphonate, while the model and control groups received subcutaneous injections of isotonic saline solution. After surgical preparation, the knee joint was dissected for Micro-CT examination, and the Micro-CT results were compared using ANOVA. In the fourth postoperative week, the bone volume fraction (BVF), trabecular number (Tb.N), and trabecular thickness (Tb.Th) of the model group were significantly lower than those of the control group (P<0.01). There was no significant difference between the Bis and control groups. In the twelfth postoperative week, BVF, Tb.Th, and Tb.N of the model group were significantly higher than those of the control and Bis groups $(\mathrm{P}<0.05)$. Similarly, bone mineral density was higher in the model group $(\mathrm{P}<0.01)$, while the trabecular spacing was significantly lower $(\mathrm{P}<0.05)$. In the early unsteady stage of the knee joint, the subchondral bone had markedly decreased, while obvious bone formation was visible in the late stage. Bisphosphonates could protect the subchondral bone structure by inhibiting bone absorption.

KEY WORDS: Osteoarthritis; Subchondral bone; 3D structure; Micro-CT.

\section{INTRODUCTION}

Osteoarthritis (OA) is a disease characterized by the gradual destruction of the knee tissues, which eventually results in loss of articular cartilage and focal exfoliation. Previous studies have focused on the effects of OA on articular cartilage, although more recent studies have revealed that the changes in the periarticular bones also play a role in OA progression. Prevention of these gradual structural changes might help reduce the destruction of articular cartilage, thereby altering the progression of $\mathrm{OA}$ and resulting in new methods for preventing and treating OArelated inflammation (Clouet et al., 2009; Yan et al., 2014; Yuan et al., 2014). The effects of changes in the structural and mechanical properties of subchondral bone on the articular cartilage are recognized by many researchers. The strength of subchondral bone relies on bone mass (bone density) and bone quality (the shape and spatial structure of the trabecular bone). Various parameters can be used to described the trabecular bone's strength, such as bone volume fraction $(\mathrm{BVF})$, bone volume $(\mathrm{BV})$, total sample volume (TV), trabecular spacing (Tb.Sp), trabecular thickness (Tb.Th), and trabecular number (Tb.N) (Batiste et al., 2004; Chiba et al., 2012). The established method for assessing the mass of subchondral bone uses dual energy Xray absorptiometry to detect bone density, although this technique does not fully reflect the strength of, or changes to, the subchondral bone. The newly developed Micro-CT method uses 3-D images to directly observe the microstructures of the trabecular bone, and can quantitatively evaluate and analyze its parameters, thereby providing a new method for studying the structure and mechanical properties of subchondral bone (Ding et al., 2008).

In the present study, a model of early OA was evaluated using Micro-CT scanning and 3-D reconstruction to visualize the 3 -D structural changes in subchondral bone. At the same time, bisphosphonate (Bis, risedronate sodium) was used as an intervention, and its protective effects on the subchondral bone were evaluated.

\footnotetext{
* Department of Orthopedics, the Second Affiliated Hospital of Soochow University, Suzhou, China.

** Department of Rehabilitation, the Affiliated Hospital of Luzhou Medical College, Luzhou, China.
} 


\section{MATERIAL AND METHOD}

Animals and grouping. Sixty healthy male New Zealand white rabbits (provided by the Animal Center, School of Medicine of Suzhou University) weighing $2.71 \pm 0.29 \mathrm{~kg}$ were used in this study. Rabbits were fed with the granulated diet, and housed in individual cages with unrestricted accessed to drinking water. Cages were maintained at an ambient temperature of $22 \pm 1{ }^{\circ} \mathrm{C}$, with alternating $12 \mathrm{~h}$ periods of natural light and darkness. The rabbits were divided into the model group $(\mathrm{n}=24)$, the Bis group $(n=24)$, and the control group $(n=12)$ using the random digits table method. Bisphosphonate was obtained from LKT Laboratories Co. (risedronate sodium, Minnesota, USA), while Micro-CT (SP mode) was obtained from GE Healthcare (London Ontario, Canada) and used for the small animal scanning. This study was carried out in strict accordance with the recommendations in the Guide for the Care and Use of Laboratory Animals of the National Institutes of Health. The animal use protocol has been reviewed and approved by the Institutional Animal Care and Use Committee (IACUC) of Soochow University.

Model duplication and specimen collection. All animals underwent knee-skin preparation 1 day before the modeling, and were weighed before the surgery. Anesthesia was performed using $20 \mathrm{~g} / \mathrm{L}$ sodium pentobarbital (Sigma Co., San Francisco, USA), which was injected through the ear vein at a dose of $30 \mathrm{mg} / \mathrm{kg}$. The animal was then fixed on the operating table in the supine position, disinfected, and covered with an operation sheet. A medial patellar incision was used to expose the joint cavity, although care was taken to avoid damaging the cartilage. In the model and Bis groups, the anterior cruciate ligament (confirmed by the drawer test) was cut, approximately $5 \mathrm{~mm}$ was removed from the middle segment, and the incision was sutured layer-bylayer. For the control group, the anterior cruciate ligament was only exposed (without any direct cut to the ligament), and the incision was sutured layer-by-layer. On the fifth postoperative day, the rabbits were intraperitoneally injected with cefazolin sodium $(500 \mathrm{mg} / \mathrm{d})$ (Shandong Lukang Pharmaceutical Group Co., Ltd., Shandong, China) to prevent infection. The injured limb was not fixed, and the animals were returned to their cages and permitted to move about freely.

The Bis group received daily subcutaneously injections of bisphosphonate $(0.01 \mathrm{mg} / \mathrm{kg})$, while the model and control groups received subcutaneous injections with an equal volume of isotonic saline solution. The rabbits were sacrificed at the designated time point (fourth, eight, or twelfth week after the surgery) using the air embolism method. Each time point included rabbits from the model group ( $\mathrm{n}=8)$, the Bis group $(\mathrm{n}=8)$, and the control group $(n=4)$. The surgical side knee was cut above and below (2 $\mathrm{cm})$ the reserved knee plane, and after removing the soft tissues, the knee was cryopreserved at $-20^{\circ} \mathrm{C}$ for $48 \mathrm{~h}$ before Micro-CT examination.

Micro-CT examination. Each knee joint sample was carefully placed in the examination slot of the Micro-CT system, and secured to prevent movement. Scanning was performed along the specimen's long axis, with a scanning protocol of $45 \mu \mathrm{m} / 24 \mathrm{R} / 18 \mathrm{~min}$. Scanning parameters were: $45 \mu \mathrm{m}$ resolution, $210^{\circ}$ rotation angle, $0.5^{\circ}$ rotation angle increment, 20 ?m interlayer spacing, $80 \mathrm{kV}$ tube voltage, $\mu \mathrm{A}$ tube current 450, $2960 \mathrm{~ms}$ exposure time, and $18 \mathrm{~min}$. Five hundred unique images (1024 x 1024 pixels) were obtained for each image, and the segmentation value was set at 1000 to complete the image binarization. The sample's complete bone tissue was set as the region of interest (ROI) for the 3-D reconstruction, which allowed for intra-bone analysis.

Quantitative analysis was performed using the Micview V2.1.2 3-D reconstruction processing software and ABA special bone analysis software. The specific measurement parameters were: BVF (\%), Tb.Th (average thickness, $\mu \mathrm{m}$ ), Tb.Sp (average canal width, $\mu \mathrm{m}$ ), Tb.N (the inverse of the average internal diameter of the structure, $\mathrm{mm}^{-1}$ ), volumetric BMD (vBMD, apparent bone mineral density, $\mathrm{mg} / \mathrm{mm}^{3}$ ), and tissue BMD (tBMD, mineral density of the trabecular bone tissue, $\mathrm{mg} / \mathrm{mm}^{3}$ ).

Statistical analysis. The data were expressed as Mean \pm SD. Statistical analysis was performed using the SPSS 13.0 statistical software package, and the intergroup comparisons were performed using analysis of variance. A P-value $<0.05$ was considered statistically significant.

\section{RESULTS}

Micro-CT imaging. The subchondral trabecular bone in the model group was rare, damaged, and twisted at each time point. In contrast, that of the control group as arranged neatly arranged, without any obvious fractures. Various degrees of osteophyte formation were observed at the edges of the joint in the model group (Fig. 1A). At each time point, the subchondral trabecular bone became progressively more rare and damaged, while the formation of osteophytes increased; the 3-D reconstruction figure clearly depicted the degeneration of the trabecular bone. The arrangement of the trabecular bone in the Bis group was significantly more 
neatly arranged, compared to that in the model group, indicating that Bis treatment protected the subchondral trabecular bone over time (Fig. 1B). Over the course of the experiment, the Bis group also exhibited less osteophyte formation at the femoral condyle edge of the knee, compared to the model group (Fig. 1C). 3-D reconstruction images of the model group at each time point revealed that osteophyte formation gradually increased over the course of the experiment (A1, B1, C1: control group; A2, B2, C2: four weeks after surgery; A3, B3, C3: 8 weeks after surgery; A4, B4, C4: 12 weeks after surgery).

Microstructural changes. The parameters of microstructural change in the model group, Bis group, and control group at each time point are listed in Table I. By the fourth postoperative week, the BVF, Tb.N, and Tb.Th of the model group had significantly decreased compared to those of the control group $(\mathrm{P}<0.01)$. The $\mathrm{BVF}$ of the model group was also lower than that of the Bis group $(\mathrm{P}<0.05)$, while the $\mathrm{BVF}$ of the Bis group was lower than that of the control group $(\mathrm{P}<0.05)$. The Tb.Sp of the model group had increased compared to that of the Bis and control groups (both $\mathrm{P}<0.01$ ). The Tb.Sp of the Bis group had also significantly increased compared to that of the control group ( $\mathrm{P}<0.01)$. The control group's BMD had significantly decreased compared to that of the Bis and control groups (both $\mathrm{P}<0.05$ ), although there was no statistical significance between the BMD of the Bis group and the control group. By the twelfth postoperative week, the BVF, Tb.Th and Tb.N of the model group had significantly increased compared to those of the control and Bis groups (all $\mathrm{P}<0.05$ ), and Tb.Sp had significantly decreased (all $\mathrm{P}<0.05$ ), while BMD had significantly increased $(\mathrm{P}<0.01)$.

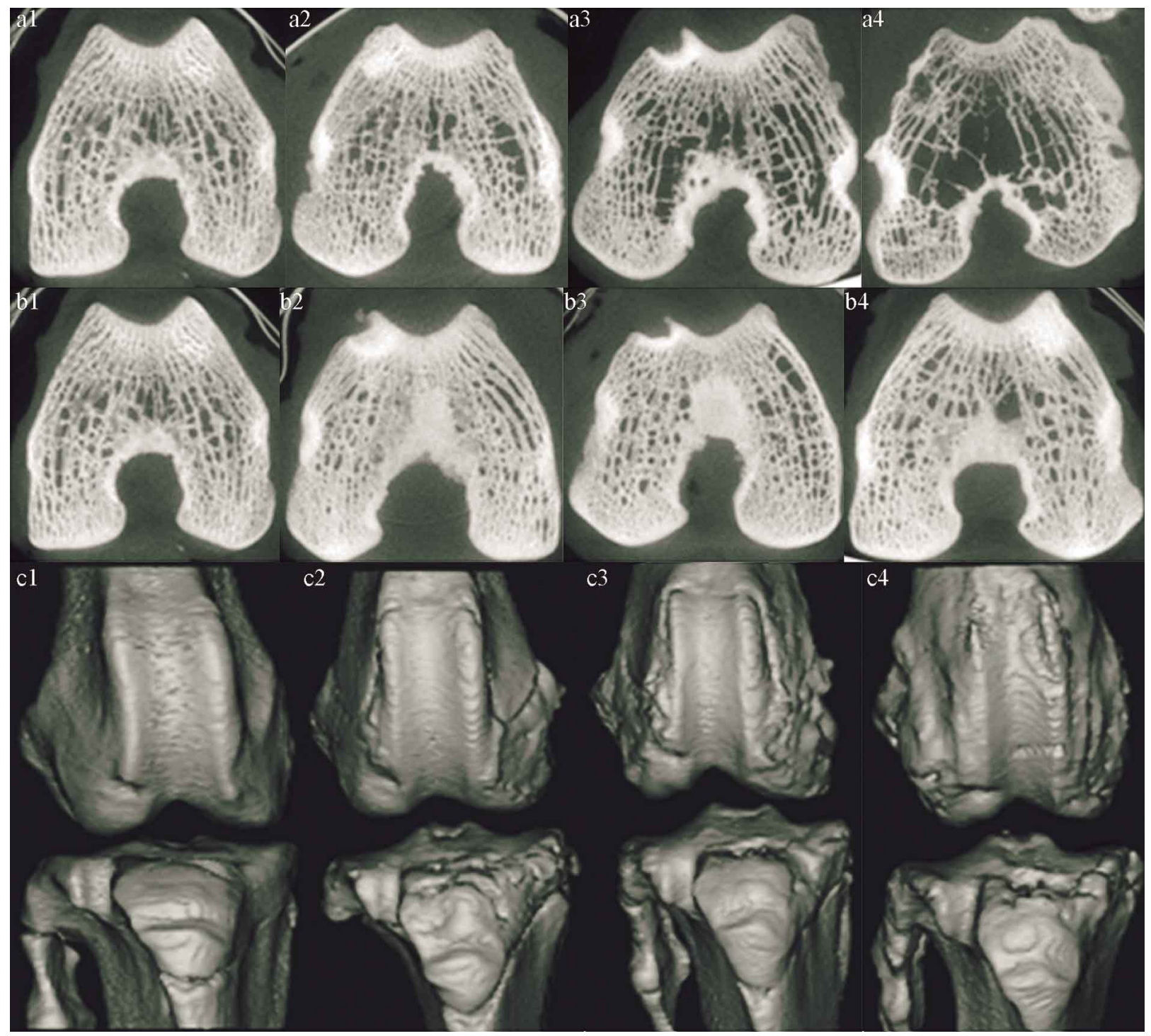

Fig. 1. 3D trabecular bone structures of femur bone cross-sections and 3D reconstruction figures of knee at different times. 


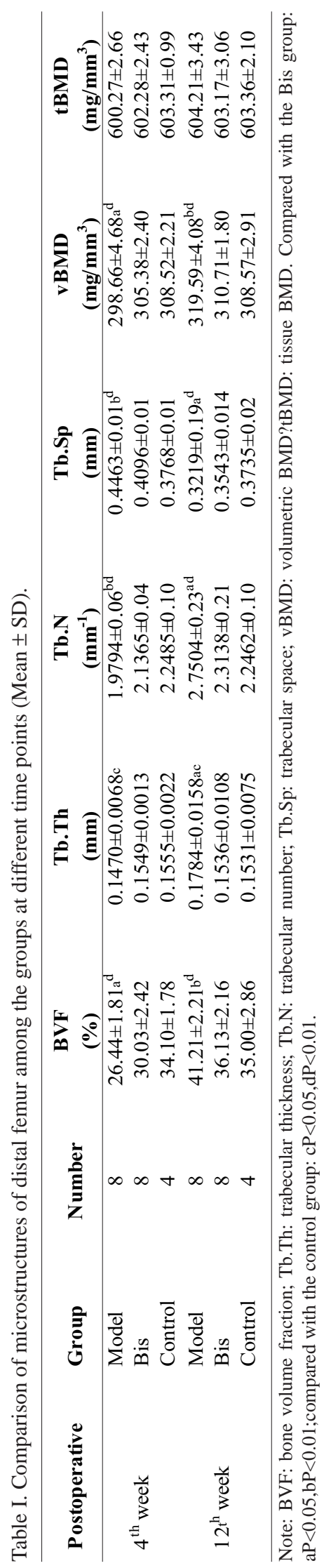

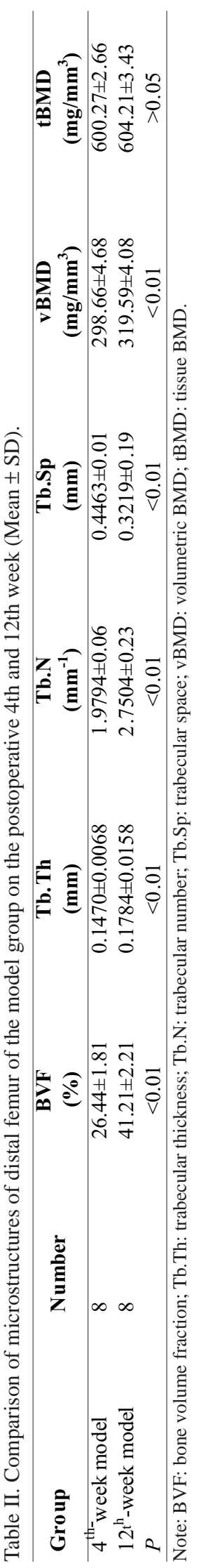

The microstructure parameters at the fourth and twelfth weeks were also compared (Table II). BVF, Tb.Th, and $\mathrm{Tb}$. $\mathrm{N}$ increased significantly over this period $(\mathrm{P}<0.01)$, while Tb.Sp decreased significantly $(\mathrm{P}<0.01)$. The bone density at the twelfth week was significantly greater than that at the fourth week $(\mathrm{P}<0.01)$.

\section{DISCUSSION}

The subchondral bone includes the subchondral cortical plate, the trabecular bone, blood vessels, and the trabecular bone cavity below the subchondral cortical plate. The cortical endplate separates the calcified cartilage and medullary cavity. The subchondral bone is supplied by a large number of arteries and veins, and branches, which penetrate the cortical endplate and enter the calcified cartilage to supply the deeper layer of articular cartilage and remove metabolic waste (Anderson-MacKenzie et al., 2005). Although it is the major structure affected by OA, the subchondral bone normally absorbs the stress placed on the articular surface, thus protecting the articular cartilage from the damages caused by excessive impact. In addition, the subchondral bone helps maintain the shape of the joint. As the elastic modules of the articular cartilage and subchondral bone are different, normal subchondral bone can become deformed, thereby conducting force away from the articular surface and into to the cortical bone and surrounding soft tissues (joint capsule, ligaments, tendons, and muscles) (Bettica et al., 2002). Therefore, the subchondral bone plays an important role in normal joint function, while protecting the articular cartilage and preventing the injuries.

The subchondral trabecular bone is mainly platelike and columnar trabecular bones (and the connective tissues), which are interconnected in the longitudinal and transverse directions to perform their mechanical function (Macneil \& Boyd, 2008). According to Wolff's law, the structural arrangements of trabecular bone are organic, and can conform to local levels of stress. Previously, bone density and mass were used in research as the physical indicators of the mechanical strength of bone tissues. Commonly used methods for bone density detection included single and dual-photon bone density detection, single and dual-energy X-ray absorptiometry (DEXA), quantitative computed tomography, quantitative ultrasound, and traditional radiography. However, the mechanical strength of bone tissues is also closely related to the microstructures of the trabecular bone, therefore, the conventional measurement methods of bone tissues appeared. 
DEXA is the most accurate of the current techniques, and is still the preferred method in many recent studies of bone density (Ding et al., 2005). This technique uses dualenergy X-rays, produced by the K-edge method, to scan the same target, exploiting the different attenuations caused by the high and low energy within the bone and soft tissues. However, computer software is needed to calculate the density of the bone tissues after eliminating the interference of soft tissues. Unfortunately, recent studies have reported that DEXA is not entirely accurate. Under stress stimuli, BMD can exhibit slight changes ( $5 \%$ to $8 \%$ ), causing the mechanical effects of the bone to vary by approximately 60 $\%$. As this technique uses 2-D scanning, it treat the bone tissues, red and yellow marrow, extra-bone muscles, and fats as bone mineral components (as they absorb the X-rays), thus resulting in inaccurateBMD measurements. This error could be up to $20 \%$ of the predicted BMD value. The bone mass, namely the form and spatial structure of the trabecular bone, is an important factor affecting the mechanical properties. Although DEXA detected the bone density, it cannot not detect the bone mass. Thus, the traditional histomorphometric assessment methods used 2-D bone tissue sections, and the calculation method of trabecular structure was based on the parallel plate-like model. However, simple 2-D images cannot not be used to determine the 3-D structure of the trabecular bones, and thus are not suitable for evaluating the 3-D anisotropy and connectivity of the trabecular bone. Although a number of new computational methods have recently been developed to evaluate the 3-D microstructure of the bone, such as the "amount of spinal astrocytes" and "pillar analysis" techniques, they face several limitations in assessing the trabecular spaces. Therefore, researchers are still searching for a practical, convenient, and accurate method to evaluate the 3-D structure of the trabecular bone (Chappard et al., 2005). Recently, MicroCT has been developed as a technique that can accurately evaluate the microscopic structures of bone tissue, and has been complemented by newly developed technology that can integrate 3-D images to fully, rapidly, and non-invasively evaluate the bone microarchitectures and bone qualities. Feldkamp et al. (1989) has used Micro-CT to evaluate the 3-D structures of cancellous bone samples, and was the first to report such findings.

In the present study, the anterior cruciate ligament was cut to establish the OA model, and experimental animals were divided into model, control, and bisphosphonate-treated groups. The purpose of this study was to evaluate the changes of subchondral bone structure in the OA model, as well as the effect of bisphosphonate treatment on the structure changes. The results revealed that, by the fourth postoperative week, the BVF, Tb.V, and Tb.Th of the subchondral trabecular bones in the model group were significantly lower than those in the control group $(\mathrm{P}<0.01)$; Tb.Sp was increased, while vBMD was decreased. These results indicate that in the early stage of OA, a variety of pathogenic factors created abnormal stress on the articular surface, causing the subchondral trabecular bone to repeatedly experience overload pressure, subsequently causing damage to the subchondral trabecular bone, and resulting in localized spinal edema, hemorrhage, and necrosis. Thus, repeated microinjuries to the subchondral bone might trigger the bone remodeling process, activating the osteoclasts, breaking down various osteolysis enzymes, and promoting localized osteolysis, subsequently causing destruction of the trabecular bone. Meanwhile, ingrowth of the new microvasculature could activate osteoblasts, forming new bone mass and osteoid. However, the calcification would likely not be sufficient. Another explanation might be that pressure at the joints caused necrosis of the local bone tissues, compressing the vessels inside the medullary cavity, thus resulting in ischemia and necrosis of local tissues, followed by the structural damage to the trabecular bone. This mechanism has been reported for intraosteal pseudocyst formation in OA subchondral bone (Nehme et al., 2003; Chapurlat et al., 2007), which is characterized by decreases in BVF, Tb.N, Tb.Th, and vBMD. As the vBMD of the subchondral bone is reduced, the structure becomes damaged, and so a reduction in its mechanical properties is inevitable. Unfortunately, this would result in a loss of transducing and buffering of stress away from the articular cartilage, leaving the articular cartilage less protected. The differences observed in the microstructural parameters of the Bis and model groups indicate that bisphosphonate can protect against destruction of the cartilage tissues. Over the course of the experiment, the BVF, Tb.N and Tb.Th of the model group significantly increased, the Tb.Sp decreased, and the vBMD increased $(\mathrm{P}<0.01)$. These results indicate that the bone formation was increased significantly in the later stage of OA. The comparison of vBMD and trabecular structures between the fourth and twelfth postoperative week revealed that BVF, Tb.N, Tb.Th, and vBMD had increased significantly $(\mathrm{P}<0.05)$, while Tb.Sp had reduced $(\mathrm{P}<0.01)$. The difference between the Bis group and the control group was not significant, indicating that following the destruction of bone tissues in the early stage of OA, bone formation in the later stage was accelerated. Although accelerated bone remodeling was observed in the early stage, the calcification was not sufficient, resulting in damage to the trabecular bone and reduced mechanical function. However, the repair and reconstruction of the subchondral bone in the later stage led to sclerosis, and hardening of the subchondral area. This uneven hardening altered the force balance on the articular cartilage, and increased the cartilage damage, although this effect was not observed in the Bis group, indicating that bisphosphonate promoted repair of the damaged subchondral 
bone (Lozito et al., 2013). In addition, the general condition of the articular cartilage in the Bis group was also significantly better than in the model group, which indicates that bisphosphonate might be used to treat the articular cartilage damage associated with OA. By protecting the integrity of the subchondral trabecular bone, and its mechanical function, the articular cartilage would be protected as normal, thus delaying the pathological development of OA (MacNeil et al., 2008; Iwamoto et al., 2010; Bobinac et al., 2013).

The mechanism by which risedronate protects the subchondral bone might involve inhibition of photolysis, which is caused by the secretion of such various enzymes, such as matrix metalloproteinases and cathepsin $\mathrm{K}$, by the osteoclasts of subchondral bone. Concurrently, bisphosphonate could promote the apoptosis of macrophages, thereby inhibiting subchondral bone remodeling, and reducing damage and sclerosis of the subchondral bone (Chiba et al., 2013; Mohan et al., 2013).

In conclusion, the decreasing bone density and structural damage to the subchondral trabecular bone observed during early $\mathrm{OA}$ might be the result excessive bone remodeling. In the later stage, increasing bone density might be attributed to bone reconstruction and the structural hyperplasia of the trabecular bone. Micro-CT was able to rapidly, easily, and non-invasively evaluate various structural parameters of the trabecular bones, and can be used in further studies of OA. We have been developing an in vivo model for future experiments, and hope to use Micro-CT examination to further study the mechanisms of OA. The efficacy of bisphosphonate in OA was further validated, and this provides hope for a more effective clinical treatment for OA.

CHEN, H.; DONG, Q. \& JIANG, W. Cambios estructurales tridimensionales del hueso subcondral y el efecto de la intevención con bisfosfonato en la osteoartritis temprana. Int. J. Morphol., 34(1):291-297, 2016.

RESUMEN: El objetivo fue observar los cambios estructurales en 3-D del hueso subcondral y los efectos de la intervención con bifosfonatos en la etapa temprana de la inestabilidad de la articulación de la rodilla. Sesenta conejos blancos New Zealand machos sanos se dividieron en tres grupos: modelo $(n=24)$, bisfosfonato $(B i s)(n=24)$ y control $(n=12)$. Las rodillas derechas de los conejos se utilizaron para evaluar los cambios estructurales. El grupo Bis recibió inyecciones subcutáneas de bisfosfonato, mientras que los grupos modelo y control recibieron inyecciones subcutáneas de solución salina isotónica. Después de la preparación quirúrgica, la articulación de la rodilla fue disecada para su análisis mediante micro-TC, y los resultados se compararon mediante ANOVA. En la cuarta semana postoperatoria, la fracción del volumen óseo (GVF), el número trabecular (Tb.N) y el espesor trabecular (Tb.Th) del grupo modelo fueron significativamente más bajos que los del grupo control $(\mathrm{P}<0,01)$. No hubo diferencia significativa entre los grupos control y Bis. En la semana 12 postoperatoria, BVF, Tb.Th, y Tb.N del grupo modelo fueron significativamente mayores que los del grupo control y Bis ( $\mathrm{P}<0,05)$. Del mismo modo, la densidad mineral ósea fue mayor en el grupo modelo $(\mathrm{P}<0,01)$, mientras que la separación trabecular fue significativamente menor $(<0,05 \mathrm{P})$. En la etapa inestable temprana de la articulación de la rodilla, el hueso subcondral disminuyó notablemente, mientras que la formación ósea obvia fue visible en la etapa tardía. Los bisfosfonatos podrían proteger la estructura ósea subcondral mediante la inhibición de la absorción ósea.

PALABRAS CLAVE: Osteoartritis; Hueso subcondral; Estructura 3D; Micro-TC.

\section{REFERENCES}

Anderson-MacKenzie, J. M.; Quasnichka, H. L.; Starr, R. L.; Lewis, E. J.; Billingham, M. E. \& Bailey, A. J. Fundamental subchondral bone changes in spontaneous knee osteoarthritis. Int. J. Biochem. Cell Biol., 37(1):224-36, 2005.

Batiste, D. L.; Kirkley, A.; Laverty, S.; Thain, L. M.; Spouge, A. R. \& Holdsworth, D. W. Ex vivo characterization of articular cartilage and bone lesions in a rabbit ACL transection model of osteoarthritis using MRI and micro-CT. Osteoarthritis Cartilage, 12(12):986-96, 2004.

Bettica, P.; Cline, G.; Hart, D. J.; Meyer, J. \& Spector, T. D. Evidence for increased bone resorption in patients with progressive knee osteoarthritis: longitudinal results from the Chingford study. Arthritis Rheum., 46(12):3178-84, 2002.
Bobinac, D.; Marinovic, M.; Bazdulj, E.; Cvijanovic, O.; Celic, T.; Maric, I.; Spanjol, J. \& Cicvaric, T. Microstructural alterations of femoral head articular cartilage and subchondral bone in osteoarthritis and osteoporosis. Osteoarthritis Cartilage, 21(11):1724-30, 2013.

Chappard, D.; Retailleau-Gaborit, N.; Legrand, E.; Baslé, M. F. \& Audran, M. Comparison insight bone measurements by histomorphometry and microCT. J. Bone Miner. Res., 20(7):1177-84, 2005.

Chapurlat, R. D.; Arlot, M.; Burt-Pichat, B.; Chavassieux, P.; Roux, J. P.; Portero-Muzy, N. \& Delmas, P. D. Microcrack frequency and bone remodeling in postmenopausal osteoporotic women on long-term bisphosphonates: a bone biopsy study. J. Bone Miner. Res., 22(10):1502-9, 2007. 
Chiba, K.; Nango, N.; Kubota, S.; Okazaki, N.; Taguchi, K.; Osaki, M. \& Ito, M. Relationship between microstructure and degree of mineralization in subchondral bone of osteoarthritis: a synchrotron radiation $\mu \mathrm{CT}$ study. J. Bone Miner. Res., 27(7):1511-7, 2012.

Chiba, K.; Osaki, M.; Ito, M. \& Majumdar, S. Osteoarthritis and bone structural changes. Clin. Calcium, 23(7):973-81, 2013.

Clouet, J.; Vinatier, C.; Merceron, C.; Pot-vaucel, M.; Maugars, Y.; Weiss, P.; Grimandi, G. \& Guicheux, J. From osteoarthritis treatments to future regenerative therapies for cartilage. Drug Discov. Today, 14(19-20):913-25, 2009.

Ding, M.; Christian Danielsen, C. \& Hvid, I. Effects of hyaluronan on three-dimensional microarchitecture of subchondral bone tissues in guinea pig primary osteoarthrosis. Bone, 36(3):489$501,2005$.

Ding, M.; Danielsen, C. C. \& Hvid, I. The effects of bone remodeling inhibition by alendronate on three-dimensional microarchitecture of subchondral bone tissues in guinea pig primary osteoarthrosis. Calcif. Tissue Int., 82(1):7786, 2008.

Feldkamp, L. A.; Goldstein, S. A.; Parfitt, A. M.; Jesion, G. \& Kleerekoper, $\mathrm{M}$. The direct examination of three-dimensional bone architecture in vitro by computed tomography. $J$. Bone Miner. Res., 4(1):3-11, 1989.

Iwamoto, J.; Takeda, T.; Sato, Y. \& Matsumoto, H. Effects of risedronate on osteoarthritis of the knee. Yonsei Med. J., 51(2):164-70, 2010.

Lozito, T. P.; Alexander, P. G.; Lin, H.; Gottardi, R.; Cheng, A. W. \& Tuan, R. S. Three-dimensional osteochondral microtissue to model pathogenesis of osteoarthritis. Stem Cell Res. Ther., 4(Suppl. 1):S6, 2013.

Macneil, J. A. \& Boyd, S. K. Bone strength at the distal radius can be estimated from high-resolution peripheral quantitative computed tomography and the finite element method. Bone, 42(6):1203-13, 2008.

MacNeil, J. A.; Doschak, M. R.; Zernicke, R. F. \& Boyd, S. K. Preservation of periarticular cancellous morphology and mechanical stiffness in post-traumatic experimental osteoarthritis by antiresorptive therapy. Clin. Biomech. (Bristol, Avon), 23(3):365-71, 2008.

Mohan, G.; Perilli, E.; Parkinson, I. H.; Humphries, J. M.; Fazzalari, N. L. \& Kuliwaba, J. S. Pre-emptive, early, and delayed alendronate treatment in a rat model of knee osteoarthritis: effect on subchondral trabecular bone microarchitecture and cartilage degradation of the tibia, bone/ cartilage turnover, and joint discomfort. Osteoarthritis Cartilage, 21(10):1595-604, 2013.
Nehme, A.; Maalouf, G.; Tricoire, J. L.; Giordano, G.; Chiron, P. \& Puget, J. Effect of alendronate on periprosthetic bone loss after cemented primary total hip arthroplasty: a prospective randomized study. Rev. Chir. Orthop. Reparatrice Appar. Mot., 89(7):593-8, 2003.

Yan, J. Y.; Tian, F. M.; Wang, W. Y.; Cheng, Y.; Xu, H. F.; Song, H. P.; Zhang, Y.Z. \& Zhang, L. Age dependent changes in cartilage matrix, subchondral bone mass, and estradiol levels in blood serum, in naturally occurring osteoarthritis in Guinea pigs. Int. J. Mol. Sci., 15(8):13578-95, 2014.

Yuan, X. L.; Meng, H. Y.; Wang, Y. C.; Peng, J.; Guo, Q. Y.; Wang, A. Y. \& Lu, S. B. Bone-cartilage interface crosstalk in osteoarthritis: potential pathways and future therapeutic strategies. Osteoarthritis Cartilage, 22(8):1077-89, 2014.

\author{
Correspondence to: \\ Qirong Dong \\ Department of Orthopedics \\ The Second Affiliated Hospital of Soochow University \\ Suzhou 215004 \\ CHINA
}

Tel: +86 51267784116

Fax: +86 51268284303

Email: qirongdong@163.com

Received: 29-05-2015

Accepted: 24-12-2015 